\title{
La decolonización del saber epistémico en la universidad*
}

The decolonization of epistemical knowledge at the university

A descolonização do saber epistêmico na universidade

Fecha de entrega: 10 de octubre de 2015

Fecha de evaluación: 15 de junio de 2016

Fecha de aprobación: 30 de junio de 2016

\author{
Francisco Chica Cañas ${ }^{* *}$ \\ José Duván Marín Gallego ${ }^{* * *}$
}

\section{Resumen}

Hace ya varias décadas que Latinoamérica salió del colonialismo "centroeuropeo", como lo llama Dussell; sin embargo, se mantiene una actitud de "colonialidad", entendida como un proceso amplio de control hegemónico de imposición de conocimientos, prácticas y formas culturales en todos los campos de la vida social, al tiempo que se desprecian y desdeñan los valores autóctonos, los conocimientos ancestrales y

* DOI: http://dx.doi.org/10.15332/s0120-8462.2016.0115.12

* Licenciado en Educación, Filosofía y Letras, Universidad Santo Tomás. Magíster en Educación Filosofía Latinoamericana, Universidad Santo Tomás. Magister en Docencia Universitaria, Universidad de la Salle. Especialista en Pedagogía para el Desarrollo del Aprendizaje Autónomo, UNAD. Especialista en Gerencia de Instituciones de Educación Superior. Correo electrónico: franciscochica@usantotomas.edu.co

* Universidad Santo Tomás; doctorado en Currículo, Profesorado e Instituciones Educativas de la Universidad de Granada, España. Actualmente forma parte del grupo Fray Saturnino Gutiérrez, O. P. Ambientes de Aprendizaje, Universidad EAN. Correo electrónico: autonomiafra9@gmail.com 
populares que Boaventura de Sousa Santos denomina con la metáfora de "las epistemologías del sur"; es decir, aquellas epistemologías de quienes no han tenido voz ni voto en las decisiones trascendentales de la vida social, económica, política y cultural, como los desposeídos, los marginados de la sociedad, campesinos, indígenas, afrodescendientes, homosexuales, entre otros.

Los responsables de esta actitud colonialista, no solamente han sido los gobiernos que, mediante convenios y tratados bilaterales y multilaterales con las potencias hegemónicas, financian proyectos de diversa índole e imponen sus criterios e intereses en los distintos campos de la economía, la política y la educación. Pero también la misma educación ha tenido su responsabilidad en este proceso. El conocimiento impartido en las universidades es hegemónico y colonizador, que llega de Europa y Norteamérica. Por esta razón, la ciencia y el conocimiento que se producen en estas regiones, debe construirse para su validez, con las epistemologías y las metodologías de estas potencias; mientras que los conocimientos culturales, populares y ancestrales, se consideran obstáculos epistemológicos que no pueden convivir e interactuar con la epistemología de la ciencia clásica.

Es por esto que la Universidad también tiene que "decolonizar" sus saberes para alcanzar un espacio transcultural que incluya todos aquellos conocimientos y cosmovisiones populares y tradicionales para que puedan ser tenidos como pares, en un diálogo de saberes dentro de los procesos de formación y aprendizaje.

Palabras clave : colonialismo, decolonización, conocimiento científico, saberes ancestrales, transculturalidad.

\section{Abstract}

For several decades now Latin America came out of the "Central European" colonialism, as Dussell calls it; however, an attitude of "coloniality" is maintained, understood as an extensive process of hegemonic control of the imposition of knowledge, practices and cultural forms in all fields of social life, while despising and disregarding indigenous 
values, the ancestral and popular knowledge that Boaventura de Sousa Santos names with the metaphor of "the epistemologies of the south"; that is to say, those epistemologies of who have had no voice or vote in the transcendental decisions of social, economic, political and cultural life, such as those dispossessed, marginalized from society, peasants, indigenous, Afro-descendants, homosexuals, among others.

The ones responsible for this colonialist attitude have not only been governments which, through bilateral and multilateral agreements and treaties with the hegemonic powers, finance projects of various kinds and impose their criteria and interests in the various fields of economy, politics and education. But also education itself has had responsibility in this process. The knowledge imparted in the universities is hegemonic and colonizing, that comes from Europe and North America. For this reason, the science and knowledge produced in these regions must be constructed for its validity, with the epistemologies and methodologies of these powers; while cultural, popular and ancestral knowledge, are considered epistemological obstacles that cannot coexist and interact with the epistemology of classical science.

This is why the University also has to "decolonize" its knowledge to reach a transcultural space that includes all those popular and traditional knowledge and worldviews so they can be considered as equals, in a dialogue of knowledge within the processes of formation and learning.

Keywords: Colonialism, decolonization, scientific knowledge, ancestral knowledge, transculturality.

\section{Resumo}

Há já varias décadas que Latino-américa saiu do colonialismo "centroeuropeio", como o chama Dussell; porém, se mantém uma atitude de "colonialidade", entendida como um processo amplo de controle hegemônica de imposição de conhecimentos, práticas e formas culturais em todos os âmbitos da vida social, ao mesmo tempo se despreza e desdenha os valores autóctones, os conhecimentos ancestrais e populares que Boaventura de Sousa Santos denomina com a metáfora 
de "as epistemologias do sul", aliás, epistemologias de aqueles que não têm tido voz nem voto nas decisões transcendentais da vida social, econômica, política e cultural, como os despojados, os marginalizados da sociedade, camponeses, indígenas, afrodescendentes, homossexuais.

Os responsáveis dessa atitude colonialista, não somente tem sido os governos, que mediante convênios e tratados bilaterais e multilaterais com as potencias hegemônicas financiam projetos de diversa índole e impõem seus critérios e interesses nos diferentes campos da economia, a política e a educação. Mas também a mesma educação tem sido responsável neste processo. O conhecimento ensinado nas universidades é hegemônico e colonizador, que chega da Europa e Norte América. Por esta razão, a ciência e o conhecimento que se produz nestas regiões, deve se construir para sua validez, com as epistemologias e as metodologias de estas potencias; enquanto isso os conhecimentos culturais, populares e ancestrais se consideram obstáculos epistemológicos que não podem conviver e interagir com a epistemologia da ciência clássica.

É por isso que a Universidade também deve "descolonizar" seus saberes para atingir um espaço transcultural que inclua todos aqueles conhecimentos e cosmovisões populares e tradicionais para que possam ser considerados pares, num diálogo de saberes dentro dos processos de formação e aprendizagem.

Palavras-chave: Descolonização, conhecimento científico, saberes ancestrais, transculturalidade.

\section{Introducción}

Educar en la era planetaria es un término que forma parte de la globalización que comienza con la diáspora del hombre sapiens, además se perciben como sociedades arcaicas que son extrañas en el ámbito de la mundialización, al tiempo que las colectividades dominantes son generadoras de violencia, esclavitud y explotación, tanto en América y África. Los pueblos que forman parte de la Epistemología del 
Sur son independientes y autónomos, aunque permanecen en una situación de poscolonialidad dominados por el cuatrimotor de la ciencia, la técnica, la industria y la economía. Sin embargo, la liberación no se logró porque se impuso las reglas y las ideas económicas, políticas, sociales y culturales de los países dominantes, tanto de Europa y Estados Unidos, constituyéndose los países no desarrollados en aprendices en el ámbito de la política, el conocimiento y la educación. De la misma manera se entiende la epistemología como un conocimiento de utilidad o no utilidad. También a ello se suma la pedida de cerebros que buscan oportunidades en el exterior para formarse en el campo de los posgrados, terminándose por quedarse en los sitios que brindan mayores oportunidades laborales y de investigación.

El occidente relegó a un segundo plano los saberes ancestrales porque se impuso la lógica del dominador, dejando a un lado el conocimiento de los pueblos aborígenes relacionado con las cosmovisiones, la ecología, la medicina, la agricultura, el arte y la estética, la generación de conocimiento por un grupo de ancianos, la inteligencia oral y los saberes ancestrales. Por otro lado, la Epistemología del Sur es un gran momento para recuperar la identidad basada en los secretos de los pueblos aborígenes, lo cual implica incorporarla en los currículos de las universidades para realizar apuestas arriesgadas en el paradigma autóctono que conciban la verdad, la belleza y la bondad desde un visión antropológica de lo que son ellos mismos como individuos y comunidad política-social. Esto significa que la Epistemología del Norte dejaría el rol protagónico de centro para dar paso a una Epistemología del Sur, que adquiere un nuevo status en torno a la vida de los pueblos que intentan superar la colonización y la dependencia del occidente.

\section{El papel de la universidad en la posmodernidad y la globalización}

Edgar Morin, Emilio Roger y Raúl Motta, en su obra Educar en la era planetaria (2006), describen la forma como se llevó a cabo el nacimiento de la era planetaria. Estos autores nos recuerdan, en primer lugar, que el término planetarización es un término más complejo que el de globalización, en el sentido de que "es un término radicalmente antropológico que expresa la inserción simbiótica, pero al mismo tiempo extraña de la humanidad en el planeta Tierra" (p. 79). En segundo lugar, que para entender la era planetaria "es preciso concebir una historia general de la humanidad que comienza con la diáspora del homo sapiens por todo el planeta, incluidas las 
islas del Pacífico" (p. 81). En tercer lugar, que esta historia general de la humanidad se lleva a cabo en dos momentos. Una primera mundialización que comienza hace decenas de miles de años con la expansión de las sociedades arcaicas por la Tierra que hizo que se volvieran extrañas y fragmentadas entre sí por la distancia, el lenguaje, los ritos, las creencias y las costumbres. Estas primitivas sociedades históricas se asentaron principalmente en Mesopotamia, Egipto, el valle del Indo y el valle del Huang Po en China. No obstante, estas mismas civilizaciones sin comunicación entre sí comienzan sin embargo "su expansión guerrera o navegante y descubren en su itinerancia la Tierra" (p. 83), gracias a los grandes conquistadores como Alejandro, Gengis Khan y Tamerlan; a la expansión de las grandes religiones como el budismo desde la India al Extremo Oriente, el cristianismo desde Asia menor al Occidente y el islamismo desde Arabia hacia los cuatro puntos cardinales; y por último, al comercio que se desarrolló principalmente en la Edad Media.

La segunda mundialización comienza en el siglo XV, con los viajes de Cristóbal Colón, Vasco da Gama, Américo Vespucio y el descubrimiento de América, las conquistas de Hernán Cortés, Francisco Pizarro y otros, y con las teorías de Copérnico que pone a girar a los planetas, incluida la Tierra alrededor del sol. En esta segunda planetarización, dice Morin et al. (2006):

La Tierra deja de estar en el centro del universo y la humanidad pierde su lugar privilegiado de la mano de la redondez de la Tierra. (...) Así como la Tierra no es el centro del cosmos, Europa no es el centro del mundo. Pero el mundo europeo va a olvidar su provincialidad preparando el desarrollo del cuatrimotor (ciencia, técnica, industria e interés económico), que impulsará a una de sus mundializaciones. Esta mundialización alcanzará su máxima expansión en la globalización económica de finales del siglo XX (pp. 86-87).

Esta nueva mundialización estará marcada por casi cinco siglos de colonización y de colonialismo que todavía no termina, cuyo desarrollo se caracteriza especialmente por "la violencia, la destrucción, la esclavitud, la explotación feroz de América y del África. Es la edad de hierro planetaria en la que aún nos encontramos" (Morin et al., 2006, p. 87).

En efecto, aunque los pueblos que fueron descubiertos en el planeta tierra durante esta segunda mundialización han alcanzado su independencia y autonomía como países, 
aún permanecen en un estado de poscolonialismo, según describe Boaventura de Sousa Santos en su libro Una epistemología del sur (2013); poscolonialismo entendido según dos acepciones principales. En primer lugar, como un periodo histórico que sucede a la independencia de las colonias, y que se traduce en un conjunto de análisis económicos, sociológicos y políticos sobre la construcción de los nuevos estados, su base social, su institucionalidad y su inserción en el sistema mundial, las rupturas y las continuidades con el sistema colonial, las relaciones con la ex potencia colonial y la cuestión del neocolonialismo, las alianzas regionales, etc. (p. 277).

En segundo lugar, como "un conjunto de prácticas (predominantemente preformativas) y de discursos que deconstruyen la narrativa colonial, escrita por el colonizador y procuran sustituirla por narrativas escritas desde el punto de vista del colonizado" (p. 277).

Tanto las ideas de Sousa Santos como las de Morin y sus colaboradores, concuerdan entre sí, en el sentido de que al lado del cuatrimotor de la ciencia, la técnica, la industria y la economía que impulsarán la máxima expansión de la globalización que tuvo su culminación a finales del siglo XX, se desarrollaron, paralelamente, las ideas emancipadoras, portadoras de una conciencia común de desarrollo humano, y que se convierten, a la vez, en un sistema de autocrítica desde dentro de la propia civilización de expansión occidental que, como ideas detonantes y contrahegemónicas, condujeron a la liberación política de las colonias.

Pero esta liberación no alcanzó, sin embargo, su plenitud, ya que las colonias se emanciparon siguiendo el modelo, las normas y las ideas políticas y culturales del centro europeo occidental, no solamente de España y Portugal, sino también de la Gran Bretaña, Francia y la Unión Soviética, no obstante que en el siglo XVIII las ideas de la Ilustración habían otorgado a la humanidad su optimismo en el poder de la razón y en el poder de organizar a fondo la sociedad, con base en principios como los derechos del hombre y del ciudadano, los derechos de los pueblos, el derecho a la libertad, la igualdad y la fraternidad de todos los seres humanos.

Por otra parte, el conocimiento y la ciencia siguieron dependiendo, y aun todavía dependen, del centro europeo. A Europa se agregó Estados Unidos, toda vez que en Norteamérica no hubo propiamente un sistema colonial, en tanto que el fenómeno que ocurrió en esta región del continente americano fue un trasplante de población que emigró y se instaló en este lugar, con todas las características, conocimientos de la época, costumbres y valores traídos del Occidente europeo, mientras que el indígena 
fue arrasado y arrinconado. Con toda razón, Carmen García Guadilla, ya desde 1981, en su libro Producción y transferencia de paradigmas teóricos en la investigación socioeducativa (1987), hace referencia al papel que han desempeñado, primero Europa y luego Estados Unidos, como los países que han ejercido la hegemonía intelectual y cultural durante estos últimos siglos, particularmente en el campo de las ciencias sociales, por medio de premisas racionalistas y progresistas en relación con la nueva visión del mundo que el capitalismo industrial y globalizante requería y que los países de la periferia habían tenido que aceptar en forma desventajosa para ellos, como en el caso de las teorías sobre el desarrollo, la economía y, muchas veces, interviniendo también en los sistemas políticos y en las formas de gobierno. Esto trajo consecuencias negativas para estos países por dos razones fundamentales: primero, porque los países periféricos tuvieron que someterse a modelos intelectuales que no correspondían a sus necesidades sociales; segundo, porque la división internacional del trabajo científico privilegiaba a los países centrales otorgándoles el papel de "maestros", mientras que los países de la periferia asumían el papel de "aprendices" y reproductores de las teorías de los maestros, lo que se ha constituido en lo que diversos autores denominan "colonialismo científico", "imperialismo cultural y científico", "dependencia científica y transnacionalización del conocimiento" (Graciarena, 1964; Galtung, 1980; Sunkel y Fuenzalida, 1975) (citados por García Guadilla, 1987).

Si ubicamos la universidad latinoamericana y colombiana en el contexto de esta segunda planetarización y globalización de finales del siglo XX, descritas por Morin, el segundo momento del poscolonialismo de Sousa Santos y la transferencia de paradigmas de García Guadilla, tendríamos que preguntarnos: ¿cuál es la situación de la universidad? ¿Cuál ha sido el papel de la universidad en esta coyuntura de poscolonialismo? ¿Qué tipo de conocimientos imparte? ¿De dónde nos vienen los paradigmas?

Sabemos bien que la universidad hispanoamericana vino a nuestro continente casi al inicio de la conquista española (a diferencia de la universidad portuguesa que inició prácticamente mucho más tarde), trasplantada al nuevo continente según el modelo de Alcalá y Salamanca, con un formato todavía medioeval y dependiendo, tanto de los poderes eclesiásticos (las bulas papales), como de la corona real (Arocena y Sutz, 2001).

Vale la pena destacar lo que afirma Tünnerman (1999, p. 22), citado por Arocena y Sutz (2001), que la universidad colonial tuvo desde esa época la pretensión de autogobernarse mediante la acción de sus claustros, la participación de los estudiantes en el claustro de consiliarios y el derecho a votar en la elección de cátedras, lo que 
constituye un antecedente de la autonomía y la cogestión universitaria, aunque no lo hubiese logrado plenamente, lo cual constituye hoy uno de los principales distintivos de la universidad latinoamericana.

Sin embargo, para algunos estudiosos latinoamericanos, entre ellos, Edgardo Lander (2000), (citado por Castro-Gómez, s.f.), la herencia colonial de la universidad latinoamericana todavía se conserva como un paradigma que reproduce, por un lado, el modelo colonialista de un pensamiento disciplinario que se mantiene y se encarna en sus procesos de enseñanza-aprendizaje y, por otro lado, la estructura y el sistema de organización son arbóreos, en el sentido de que "los conocimientos tienen unas jerarquías, unas especialidades, unos límites que marcan la diferencia entre unos campos del saber y otros, unas fronteras epistémicas que no pueden ser transgredidas, unos cánones que definen sus procedimientos y sus funciones particulares" (p. 81). Además, vista la universidad como el lugar donde se produce el conocimiento:

Funciona más o menos como el panóptico de Foucault, porque es concebida como una institución que establece las fronteras entre el conocimiento útil y el inútil, entre la doxa y la episteme, entre el conocimiento legítimo (es decir, el que goza de "validez científica") y el conocimiento ilegítimo (Castro-Gómez, s.f., p. 81).

Sostiene también Castro-Gómez que la universidad se inscribe en lo que él quisiera llamar "la estructura triangular de la colonialidad: la colonialidad del ser, la colonialidad del poder y la colonialidad del saber" (pp. 79-80).

No quiero detenerme en la colonialidad del ser ni del poder, sino en el del saber, aunque los tres se relacionan íntimamente. Somos conscientes de que el conocimiento que se produce y que sirve a los intereses del Estado y de la sociedad, no es el que se produce en la misma universidad, sino el que es producido e importado de las empresas, la industria y los grandes centros especializados o "centros de excelencia" transnacionales de Europa y de Estados Unidos, los cuales no solamente difunden el conocimiento, sino que también lo controlan y lo imponen a estos países, mediante diversos mecanismos directos o indirectos. En forma directa, primero, porque pueden invertir millones de dólares en ciencia y tecnología que transfieren a estos países; segundo, pueden invitar y contratar a científicos y profesores más prestigiosos del mundo; tercero, atraen, a través de la oferta de sistema de becas, a los estudiantes más capacitados de estos países periféricos, los cuales van en busca de un Ph.D., en alguna 
de estas prestigiosas universidades que ocupan los primeros lugares en el ranking mundial (García, 1987). Sabemos también que generalmente estos estudiantes, por una parte, no regresan a su país de origen porque este no les brinda las suficientes oportunidades de trabajo o posibilidades de investigación, y por otra parte, realizan sus tesis de maestría o doctorado con base en los problemas de los países a los cuales pertenecen, pero estos conocimientos infortunadamente tampoco regresan a sus sitios de origen para la solución de los problemas, sino que se quedan allí para beneficio, control y uso de los centros hegemónicos del conocimiento.

En relación con las formas indirectas de producción, difusión y control del conocimiento, García Guadilla (1987) argumenta que:

La difusión del conocimiento toma también formas indirectas; a través de los circuitos de distribución de material especializado (libros, revistas, periódicos, etc. [Bases de datos especializadas]). Esta difusión tiene como base circuitos de información y de asociación científicamente legitimados, que están también bajo el control de los países que producen el conocimiento. Para algunos autores, el tercer mundo no ejerce sino un papel de consumidor en sus intercambios intelectuales con los países del "centro", experimentando de esta manera una balanza comercial desventajosa de sus productos intelectuales (véase Altbach, 1978) (García, 1987, p. 16).

Por otro lado, la universidad no solamente privilegia este conocimiento venido desde el centro, con sus epistemologías y sus metodologías, como el único conocimiento válido en sus procesos de enseñanza-aprendizaje, sino que desdeña cualquier otro conocimiento que no esté dentro de los cánones de lo que generalmente se conoce como lo clásico, lo tradicional. Mientras que los conocimientos ancestrales y locales, como el mito y las creencias populares, con las cuales, sin embargo, las comunidades resuelven muchos problemas, carecen de sentido, pertenecen al campo de lo folclórico y se vuelven obstáculos epistemológicos para el conocimiento científico que se debe enseñar en la universidad, pues, como señala Panikkar (en Bermejo, 2008), se trata de la superación del reduccionismo epistemológico y racional, es decir, "la reducción del conocimiento a la inteligibilidad racional (...), a fin de que se permita "hacer entrar en el campo del conocimiento humano otros fenómenos que escapan a la red de la inteligencia racional" (p. 211). 
Decolonización e incorporación de los conocimientos ancestrales a los paradigmas de la ciencia, mediante un proceso de construcción y de diálogo saberes. El occidente impuso el imperativo categorico científico que relegó a un segundo plano los saberes ancestrales, al negar el potencial cognitivo de los indígenas, en cuanto que los conquistadores y los colonizadores minimizaron, sistemáticamente, los saberes dentro de la dinámica y la lógica del poder dominante que desconocía una epistemología enraizada en las cosmovisiones y en las producciones técnicas de la artesanía, la arquitectura, la astrología, el manejo de la tierra y el clima, la utilidad de las plantas medicinales entre otros. Esto quiere decir que se tiene que incorporar una Epistemología del Sur para dialogar con un nuevo paradigma de la ciencia que retome el conocimiento de la periferia para convertirlo en el centro de un legado de teorías y de prácticas que poseen en el fondo una razón de identidad, una razón discursiva de orden científico que se nutre de experiencias cotidianas y de las visiones imaginarias del mundo, de los presaberes, de las hipótesis que trasiegan en medio de mitologías y dioses.

La construcción y el diálogo de saberes de los ancestros no parten de una relación con el conocimiento científico cultural europeo, es todo lo contrario, el referente está fincado en los saberes de la ecología y en el conocimiento político de la comunidad. De ahí que, Ramírez Eras (2001) afirma de la existencia de conocimientos relacionados con "la medicina natural, las estructuras binarias, vigesimales, decimales de la matemática, taxonomías propias de plantas, animales, de seres bióticos y abióticos" (p. 6) en el marco de un visión cosmológica del mundo. Por esta razón, el diálogo con la Epistemología del Sur debe partir de la problemática que está viviendo el mundo contemporáneo en torno al manejo de los recursos naturales y el cuidado del medio ambiente, tomando como referente el saber de las comunidades indígenas para replicar estas experiencias frente a una sociedad depredadora y consumista.

Es importante resaltar el enfoque ecológico de los indígenas para la explotación de la agricultura, tal como lo plantea Gondard (2006), como el avenamiento de los suelos y el drenaje de los sitios, la creación de ecosistemas para mantener las tierras húmedas, el control del riego en época de humedad, el uso de fertilizantes a partir de las limpiezas de las zanjas, la elaboración de canales para contener la crecida de los ríos, el auge del pescado ahumado como resultado de un comercio regional interno, las vastísimas regiones sembradas de yucales, las piscinas construidas para labores de piscicultura, las zanjas húmedas como productora de verduras y el uso apropiado de los camellones, entre otros. Estas experiencias en el campo de la agricultura es 
una muestra palpable del ingenio y creatividad de los ancestros para afrontar con un sentido común el quehacer complejo de la vida en el contexto social de las comunidades, que hoy en día se convierte en una premisa rectora acerca del manejo de los recursos naturales.

Por otra parte, hablar de comunidades científicas indígenas, tal como lo concibe y lo entiende el mundo occidental, es impensable en cuanto a las comunidades primitivas; sin embargo, es importante rescatar los medios y métodos que emplea para trasmitir de generación a generación los saberes en manos de un grupo de ancianos que encarna la esperanza de la vida de estos grupos. Esto quiere decir que las comunidades académicas y científicas tienen que jugar un rol protagónico de diálogo para recuperar la inteligencia oral y de síntesis, con el fin de no perder la tradición, las creencias, las costumbres, las concepciones mitológicas y el modo de habérselas en el mundo. Mientras comisiones científicas europeas establecen contactos con los aborígenes para apropiarse los saberes de plantas medicinales, de concepciones de arquitectura, de sistemas sociales y de otras riquezas que brinda el mundo tierra; no cabe duda que este fenómeno no se repite de la misma forma en América Latina y otros sitios de países no desarrollados, al no proteger los tesoros ancestrales y la falta de interés por dialogar y refundir en los sistemas educativos aquello que es propio de la Epistemología del Sur.

La recuperación de la memoria ancestral debería constituirse en un proyecto transversal de las escuelas y las universidades para concientizar a los jóvenes de la historia, la geografía, la política, la cultura, el arte y la estética de las comunidades aborígenes. Esto contribuiría a mantener vivo el legado cultural de las comunidades ancestrales para impactar, ojalá, como sucedió con la filosofía de la agenda griega que cada vez adquiere más relevancia en el mundo actual. Por ende, Ramírez Eras (2001) sostiene que "el avance de la modernidad ha significado y significa la pérdida cotidiana de conocimientos, de referentes, de códigos culturales que ahora es imprescindible rescatar" (p. 7). Entonces, las instituciones educativas han excluido del currículo las tradiciones de los pueblos aborígenes fortaleciendo la Epistemología del Norte que sobreabundando en asuntos científicos y de reproducción del conocimiento, como en cuestiones inútiles que impone el mundo secularizado del consumo y la oferta.

También es importante reconstruir la cultura epistémica de los indígenas para tener un hilo conductor del modo como se gesta el conocimiento relacionado con la forma de acceder a la verdad respecto al uso de la tierra, de las plantas medicinales, de la 
organización social y política, la relación con el medio ambiente, la utilización de los recursos naturales, el horizonte antropológico, la concepción ética y moral desde la perspectiva de las cosmovisiones y el naturalismo de la vida. De igual manera, Morin (2011) sostiene que los hombres primitivos han trasegado por la vida inventando herramientas, juguetes, han construido casas, han recogido forraje, han confeccionado vestidos y vasijas, han desarrollado técnicas de caza y aptitudes sensoriales para sobrevivir. Por tanto, se puede inferir que los indígenas deben ocuparse de investigar la propia subjetividad epistémica de la cultura, del mismo modo, las comunidades científicas tendrían que desplegar un proyecto audaz de diálogo que trascienda las fronteras de un conocimiento centrado en la racionalidad europea para cambiarlo por un discurso de la periferia. O sea que, en el instante que la universidad cambie el chip de lo instrumental de la cultura occidental por lo racional e irracional de las culturas ancestrales, de inmediato la mirada adquiere el status de la Epistemología del Sur.

Por otra parte, no se puede desconocer el aporte artístico de las culturas ancestrales, en el caso de la comunidad Inga de Santiago Putumayo (Colombia) en la que se plasma lo cotidiano del quehacer indígena en torno a las cosmovisiones del mundo, lo religioso y las invasiones de los conquistadores. Por ello, autores como Jacanamijoy y Bastidas (2007) manifiestan que la globalización excluye el arte Inga y la identidad de la vida comunitaria porque genera incertidumbre alrededor de las creencias, las costumbres, la organización social y política. Del mismo modo, las culturas indígenas milenarias siempre se han expresado por medio del arte en la que refleja las creencias, el comportamiento y las actitudes a través del transcurrir del tiempo (pasado, presente y futuro) histórico. Además de las imposiciones del mundo occidental en términos de evangelización y cultura que converge en un sincretismo entre la religión cristiana y la identidad antropológica del indígena, considerando la producción de estos grupos como mero artefactos frente a la producción artística del occidente.

Esto significa que el occidente impone un imaginario de la verdad, de la bondad y de la belleza que no tiene correspondencia con la expresión artística de los pueblos indígenas porque el referente se sustenta en la cotidianidad, en el diálogo del hombre con la naturaleza, en las creencias, en los mitos y las leyendas de los pueblos, tal como lo sostiene Jacanamijoy Chasoy y Bastidas Jacanamijoy (2007). El diálogo de saberes debe tener en cuenta la idiosincrasia de los pueblos indígenas, lo que implica pensar y sentir en términos de la periferia de la Epistemología del Sur, para replantear los paradigmas educativos escolares y universitarios con un enfoque de 
reconocimiento - dialógico de la localidad frente a la globalización- para que el discurso de la Epistemología del Norte tenga actitud de escucha, de entendimiento, de interpretación, de análisis, de compromiso hacia lo extraño y lo foráneo, el cual se caracteriza por un paradigma del color, de la peculiaridad de la lingüística, de la vestimenta, de la artesanía, del amor, de la estética, de la identidad y los ancestros.

El diálogo de saberes de los pueblos ancestrales tiene que tocar la médula de las instituciones educativas en torno a la concepción artística para comprender la carga de contenido visual y simbólico, la interacción con la naturaleza y los congéneres, las representaciones iconográficas, las leyendas, las mitologías, los cuentos, el encuentro y la reconciliación, la relación con la madre tierra, tal como lo plantea (Jacanamijoy y Bastidas, 2007). Esto quiere decir que las entidades educativas tienen que incorporar en los currículos apuestas arriesgadas acerca de las tradiciones de los pueblos ancestrales como un eje transversal-problematizador que dialogue con las disciplinas, la ciencia, la tecnología y la cultura de la Epistemología del Norte, lo más seguro es que esta fusión de cocteles desencadenará en emociones y reflexiones cognitivas eclécticas del conocimiento, que obligará incorporar profesionales de otros ámbitos, como antropólogos, geólogos, ingenieros ambientales, músicos y artistas que rompan con esos currículos rígidos y carentes de prácticas tradicionales. En otras palabras, el diálogo de los saberes ancestrales debe estar fincado en los pilares de la educación escolar y universitaria para formar generaciones sensibles en torno a la tradición de los pueblos aborígenes.

Por otro lado, los pueblos ancestrales presentan un conocimiento profundo sobre el papel de la medicina tradicional, los actores y los roles que están implicados en torno al enfoque de la sanación, con una experiencia de dominio del entorno y la naturaleza que posibilita la curación, en gran parte, de la población. Cardona Arias (2012) sostiene que la medicina tradicional articula al indígena con la naturaleza, la vida y la espiritualidad basado en la propia concepción que posee de la salud, las explicaciones e interpretaciones que realizan sobre las rutas de las enfermedades e incorporando las plantas, el papel de los espíritus y los animales. Ahora, la sanación es un factor decisivo para llevar a cabo una limpieza y facilitarle una protección para que la enfermedad no se vuelva a presentar y aprovechando al máximo todos los recursos que ofrece la naturaleza. Tampoco se puede dejar a un lado los espíritus guardianes que están ubicados en sitios sagrados y que forman parte de la iconografía indígena. También los actores involucrados con el sistema médico se jerarquiza de 
acuerdo con el siguiente orden: en el nivel primero el saber de las abuelas o madres, en el nivel segundo los sobanderos, en el nivel tercero rezanderos y curanderos, en el cuarto las parteras y en el quinto los médicos tradicionales.

Estas prácticas de la medicina tradicional son desconocidas en el mundo occidental porque carecen del rigor científico que impone el mundo del positivismo, y no forman parte del currículo de las escuelas y las universidades. No obstante, es importante rescatar la intuición y los saberes que poseen los chamanes del entorno y de la naturaleza con un aire de misterio, con el fin de guardar ese inventario en las mentes del mundo de la academia y la ciencia, lo cual contribuiría a valorar el herbario y las plantas medicinales de las diferentes localidades del mundo para salvar vidas, y no depender de los medicamentos de las multinacionales farmacéuticas que tienen un gran interés comercial y económico. Realmente en el campo de la salud los pueblos de América Latina pierden la identidad cuando dejan que la memoria de la medicina tradicional sea capturada por proyectos de investigación que emprendieron los países europeos y otros grupos económicos, desde la época de la conquista, haciéndolo con un interés de lucro. Además, la falta de política por parte del Estado por guardar la medicina tradicional como una práctica de medicina alternativa para aquellas comunidades pobres y marginadas que no cuentan con suficientes recursos económicos para comprar la medicina de la Epistemología del Norte.

El puente del diálogo entre los conocimientos ancestrales y la ciencia está mediada por un interés de querer descubrir los secretos de los antepasados para explotarlos con una visión capitalista. Esto quiere decir que no es un diálogo sincero y honesto porque en el fondo se impone un paradigma de dominación que esta permeado por el signo pesos. ¿Cuántos de estos descubrimientos que han terminado en el legado del mundo occidental no se han devuelto con un sentido de reciprocidad, hermandad y humanidad? Como se sabe, ha sucedido todo lo contrario, llegan las medicinas procesadas y terminadas a los pueblos que forman parte de la Epistemología del Sur para que sean compradas por un valor superior a lo que sustrajeron de las comunidades indígenas. De este modo, el diálogo se opaca por el interés cientificista y económico que imponen los países desarrollados; además, los dominados se muestran complacientes y generosos de seguir facilitando la usurpación de recursos a cambio de un beneficio económico que no cubre las necesidades de los pueblos de Centro América, América Latina, África, Asia y Medio Oriente. 
El diálogo entre la ciencia del occidente y los conocimientos ancestrales requiere de una reorganización que ubique en el centro a la Epistemología del Sur y deje en la periferia a la Epistemología del Norte. Esto significa educar a los dominantes y los dominados para asumir una actitud de escucha, de compromiso, de entendimiento, de reciprocidad, de reconocimiento, de revaloración del quehacer científico, de cambio de posiciones, de repotenciar la curiosidad por la otredad, de ver en lo icónico del simbolismo indígena el germen de una cultura, tan diferente y cercana, a los problemas de origen e identidad de los pueblos aborígenes. La dificultad del diálogo más grave radica en que la secularización, la oferta y la demanda, el cientificismo, la exclusión, la imposición de conocimientos y discursos hegemónicos, las modas, la pérdida de memoria histórica y el esnobismo son grandes obstáculos que implican una compenetración de vaso comunicante entre lo local y lo global, esta es una utopía que se mantendrá en el transcurso de la historia y que retará a las futuras generaciones.

\section{Conclusiones}

El diálogo entre la ciencia contemporánea para incorporar los conocimientos ancestrales es un reto muy arriesgado porque son más los contra que los pro en torno a un reconocimiento del quehacer aborigen por parte del mundo occidental. Esto quiere decir que la educación escolar y universitaria se mueve con currículos reproductivos que excluyen de antemano la herencia con los pueblos aborígenes por dar prioridad a los contenidos de las disciplinas del mundo neoliberal sustentado en la economía, la productividad, la rentabilidad, la oferta y la demanda, la moda y la imposición de racionalidades técnicas y tecnológicas. Entonces, es un diálogo totalmente asimétrico que la racionalidad global intenta desconocer por considerarla como un pensamiento no genuino que no responde a los estándares de esos grandes edificios elaborados por la ciencia y la tecnología.

La decolonización e incorporación de los saberes ancestrales no es un asunto urgente del mundo académico y mantiene la postura de inercia. Por tal motivo, se requiere una agenda que piense los pueblos aborígenes como un sistema ecológico, social, político, natural, económico y educativo que tiene una diversidad de aristas con significados basados en la espiritualidad de la naturaleza, la madre tierra, las costumbres, las creencias, los roles de los integrantes de la comunidad, el papel de la familia, el arte y la estética, las prácticas peculiares de la agricultura, las medicinas tradicionales obtenidas de plantas medicinales, el papel protagónico del chaman y 
las parteras. Es decir, se tiene que construir una Epistemología del Sur con base en las categorías de la Epistemología del Norte para que hable la semiótica de lo negado, de lo desconocido, de lo explotado, de lo humillado, de lo violentado, de lo poético, de lo simbólico y lo icónico de los pueblos ancestrales.

\section{Referencias}

Arocena, R., y Sutz, J. (2001). La universidad latinoamericana del futuro. Madrid: Editorial Biblioteca Nueva.

Dreher, J. (2012). Reflexiones sobre creatividad: el poder de subjetivación del ser humano. Cuadernos de Filosofía Latinoamericana, 33(106), 15-25.

Tendencias-Escenarios-Alternativas. Universidad de la República Oriental del Uruguay. México: UDUAL. Recuperado de: http://www.oei.es/salactsi/sutzarocena00.htm

Cardona, J. A. (2012). Sistema médico tradicional de comunidades indígenas Emberá -Chamí del Departamento de Caldas- Colombia. Recuperado de http://www. scielosp.org/pdf/rsap/v14n4/v14n4a08

Castro-Gómez, S. (s.f.). Decolonizar la universidad. La hybris del punto cero y el diálogo de saberes. Recuperado de http://www.ram-wan.net/restrepo/decolonial/14castro-descolonizar\%20la\%20universidad.pdf

García, C. (1987). Producción y transferencia de paradigmas teóricos en la investigación socio-educativa. Caracas: Fondo editorial Tropykos.

Gondard, P. (2006). Campos elevados en llanuras húmedas. Del modelado al paisaje. Camellones, wauru, warus o pijales. Recuperado de http://horizon.documentation. ird.fr/exl-doc/pleins_textes/divers09-03/010039069.pdf

Jacanamijoy, E., y Bastidas Jacanamijoy, L. (2007). Estudios sobre los simbolismos en las manifestaciones artísticas visuales de la comunidad indígena Inga de Santiago, Putumayo. Recuperado de http://aprendeenlinea.udea.edu.co/revistas/index.php/ revistaeyp/article/viewFile/6642/6085 
Morin, E., Ciurana, E., y Motta, R. D. (2006). Educar en la era planetaria. (1. ${ }^{\mathrm{a}}$ reimp.). Barcelona: Gedisa.

Morin, E. (2011). La vía para el futuro de la humanidad. Barcelona, España: Paidós.

Panikkar, R. (2008). ¿Aprender de la paraciencia? Contra el reduccionismo epistémico. En Bermejo, D. (Ed.). Las fronteras de la ciencia. Barcelona: Universidad de la Rioja - Anthropos.

Ramírez, A. M. (2001). Problemas teóricos del conocimiento indígena. Presupuestos e inquietudes epistemológicas de base. Recuperado de http://icci.nativeweb.org/ yachaikuna/1/ramirez.pdf

Santos, B. de S. (2013). Una epistemología del sur. (4. ${ }^{a}$ reimp.). México: Siglo XXI-CLACSO.

Villa, W. (2013). Memoria y pedagogización del mal-decir: una aproximación a los recorridos literarios que inventan mundos. Cuadernos de Filosofía Latinoamericana, 34(108), 79-107. 